\title{
An Unusual Presentation of Merkel Cell Carcinoma
}

\author{
Kamuran İbişs ${ }^{1}$ Mert Saynak1, Taner Akalın², Dilek Nurlu ${ }^{1}$, Sernaz Uzunoğlư ${ }^{3}$ \\ ${ }^{1}$ Department of Radiation Oncology, Faculty of Medicine, Trakya University, Edirne, Turkey \\ ${ }^{2}$ Department of Pathology, Faculty of Medicine, Ege University, Izmir, Turkey \\ ${ }^{3}$ Department of Medical Oncology, Faculty of Medicine, Trakya University, Edirne, Turkey
}

\begin{abstract}
We describe a 71-year-old male patient admitted to the hospital with posterior chest pain. Following the detection of a paravetebral mass at the level of the $2^{\text {nd }}$ thoracic vertebra, the patient underwent a surgical en bloc resection of the mass. The histopathologic examination revealed a Merkel cell carcinoma. One month after the operation, magnetic resonance imaging showed an inoperable mass in the same location, which indicated a rapid progression of the tumor. The patient died of progressive respiratory failure due to pneumonia on the $6^{\text {th }}$ day after the onset of radiochemotherapy. Although this appears to be an isolated case, Merkel cell carcinoma must be included in the differential diagnosis of intrathoracic masses.
\end{abstract}

Key Words: Merkel cell carcinoma, intrathoracic, extracutaneous

Received: 20.12 .2010

Accepted: 07.03.2011

\section{Introduction}

Merkel cell carcinoma (MCC) is an uncommon primary cutaneous neoplasm of neuroendocrine cells with a predilection for the head and neck and distal extremities in elderly patients. It is principally a disease of the Caucasian race with an incidence of 0.44 per 100,000 and is very high (8\%) among immunsuppressed patients $(1,2)$. The disease course is difficult to predict and ranges from relatively indolent to highly aggressive, often spreading to local, regional, and distant sites $(3,4)$.

MCC very rarely arises outside the skin. In the literature, the salivary glands, nasal cavity, lymph nodes, and subcutaneous fat have been reported as the most common extracutaneous sites (5-8). We describe a 71-year-old man with Merkel cell carcinoma, which presented as an intrathoracic mass. To the best of our knowledge, this is the first described case in the English-language literature of such a lesion located intrathoracically with no detectable primary site.

\section{Case Report}

A 71-year-old male presented to the Thoracic Surgery department with an 11-month history of left-sided posterior chest pain. He had smoked one packet of cigarettes daily for 35 years but had given up the habit one year before admission. On physical examination, no rash or lymphadenopathy was detected. Laboratory results and chest radiography were normal. Computed tomography of the thorax showed a paravertebral mass $(41 \times 21 \mathrm{~mm}$ in diameter), extending to the neural foramen of the $2^{\text {nd }}$ and $3^{\text {th }}$ thoracic vertebrae in the apical-posterior segment of the left upper lobe. The transthoracic fine-needle aspiration biopsy revealed a malignant tumor. Positron emission tomography scan showed a hypermetabolic malignant lesion in the apical-posterior segment of the left upper lobe, with no hypermetabolic lesions in the mediastinum (Figure 1). No other lesions, primary or metastatic, were demonstrated.

The patient underwent en bloc chest wall resection with parietal pleura, facets and transverse processes of the throracic vertebrae ( $2^{\text {nd }}$ and $\left.3^{\text {th }}\right)$, and intercostal muscles. On exploration, the lesion with a lobulated contour appeared to invade the thoracic vertebrae and an intrathoracic but extrapulmonary location.

The histopathological examination showed a tumor characterized by small indefinite nests and solid areas consisting of small and round cells with narrow cytoplasm. Tumor necrosis and tumor thrombi were also recognised. Macroscopically, the tumor did not show bone invasion. At first glance, malignant small round cell tumors namely; metastasis of small cell carcinoma, metastasis of melanoma, PNET/Ewing sarcoma and Merkel cell carcinoma were considered histologically. By means of immunohistochemistry, some possibilities were exluded. Cytokeratin 7 and TTF-1 were negative for metastasis of small cell carcinoma, S-100 and HMB-45 were negative for malignant melanoma and CD-99 was negative for PNET/Ewing sarcoma. Specific cytokeratin 20 positivity with specific globular pattern enabled us to label the tumor as Merkel cell carcinoma (Figure 2).

No suspected skin lesion or lymph nodes were detected after careful physical examination of the patient. The patient had no history suggesting an immuno-compromised status 


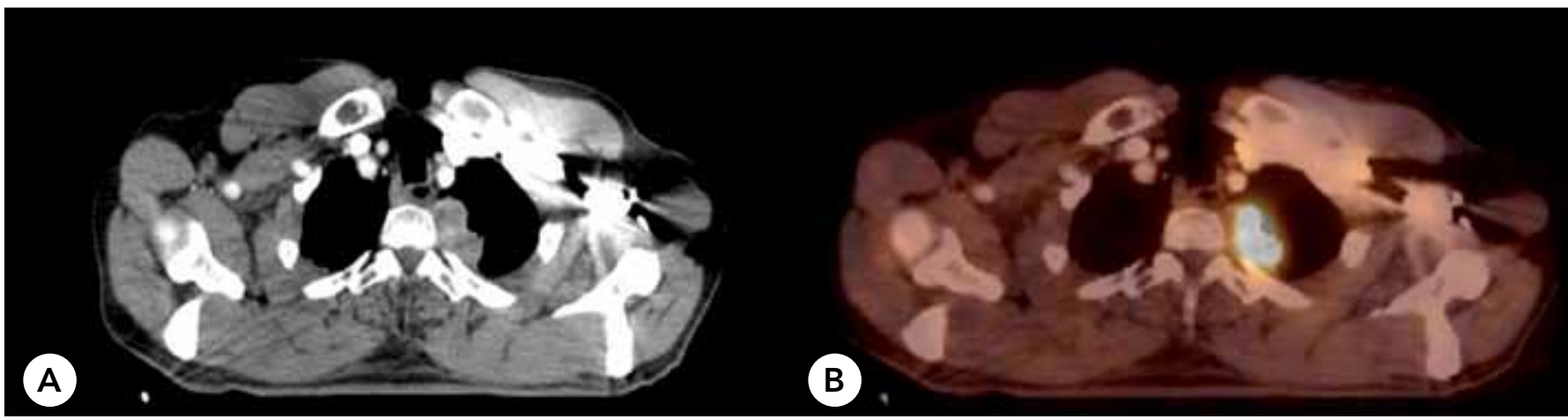

Figure 1. A: Computed tomography scan shows the left intrathoracic mass B: Positron emission tomography and superimposed computed tomography scan shows the left intrathoracic hypermetabolic malignant mass

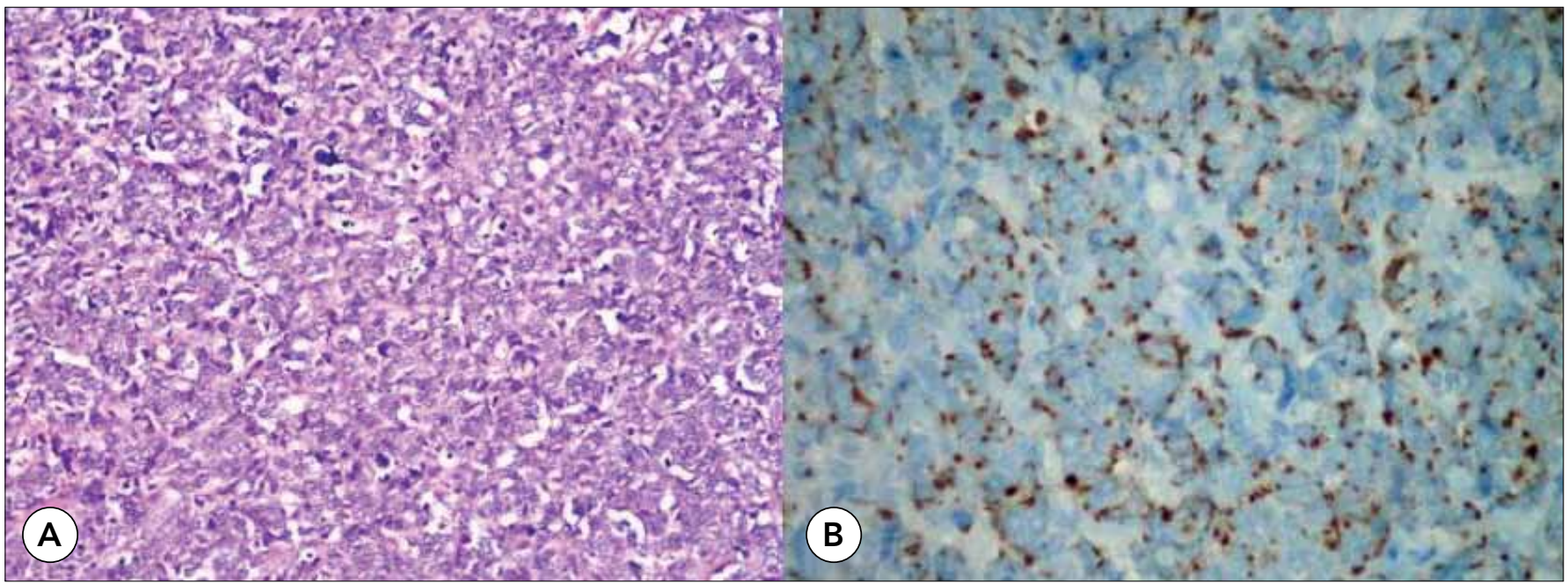

Figure 2. A: Solid tumor areas composed of atypical small round cells (HEx200). B: Globular cytokeratin 20 positivity in cytoplasms of tumor cells (Immunoperoxidase cytokeratin $20 \times 400$ )

and human immunodeficiency virus infection was excluded by the appropriate laboratory tests.

The patient was referred to the Oncology department for adjuvant treatment one month after the operation. Magnetic resonance imaging of the thorax showed a mass with dimensions of $28 \times 15 \mathrm{~mm}$ in the same location, which was apicomedially adjacent to the corpus of the $2^{\text {nd }}$ thoracic vertebra, and the mass was also expanding into the neural foramen. It was thought to be a rapid progression of the tumor. The tumor was inoperable and concomitant radiochemotherapy was planned. He developed severe pneumonia six days after the onset of the radiochemotherapy and died despite the rapid onset of broad spectrum antibiotherapy two days after the diagnosis of pneumonia.

\section{Discussion}

MCC is rare, with an estimated annual incidence of 0,2 and 0,45 cases per 100,000 (9). MCC is extremely rare before the age of 50 years, after which the incidence increases steeply with age. The incidence is increased approximately 11-fold for people with AIDS and five-fold for people who have undergone an organ transplantation $(9,10)$. The risk of MCC may be particularly high with prior psoralen and UV-A treatment, which reinforces the likely etiologic role of UV radiation (11). In the current case, there was no such history.

Fredrick Merkel first described Merkel cells in 1875 as mechanoreceptors in the basal layer of the epidermis. An epithelial origin is possible, but some data suggest that Merkel cells may have a neural-crest origin (12). Cyril Toker first published a series of skin neoplasms of the elderly with special histologic characteristics between 1966-1970 (13).

Microscopically, the tumor nodule of MCC is comprised of small cells with scant neoplasm, large nuclei and finely granular chromatin. Accurate diagnoses of neuroendocrine carcinoma is difficult due to its similarity to other poorly differantiated "small blue cell tumors", like small cell carcinoma of the lung. Immunohistochemistry is an essential tool in the routine diagnosis of MCC. MCC cells stain negatively for S-100 protein which is positive in melanoma, for TTF-1 and CK-7 which is positive in smallcell lung carcinoma, and for LCA which is positive in lymphoma. Combined immunostaining for TTF-1 and CK20 can be used for differentiating MCC from small cell lung carcinoma (14). A CK20 positive and TTF-1 negative result in a tumor morphologically consistent with MCC establishes the diagnosis (15). In the present case, diffuse globular CK20 positivity and TTF-1 negativity were detected. Additionally, MCC cells stain positively for neuroendocrine markers chromogranin and synaptophysin. 
MCC almost always arises from the dermis. It occurs extremely rarely outside the skin. In the literature, the salivary glands, lymph nodes, subcutaneous fat and nasal cavity, are the reported extracutaneous sites with no detectable skin primary $(6-8,16)$. However, no case of MCC located intrathoracically with no detectable skin primary have been reported. Actually, it is very difficult to decide that the intrathoracic mass is primary or metastatic in the current case. The hypothesis that MCC may originate from a pluripotent cell has gained recent support. This hypothesis could help to explain the origins of both skin and non-skin tumors (17).

Currently, there is no a standard therapy protocol for MCC. The treatment of choice depends on the extension of the disease. Local excision is preferred in localized disease, whereas a wide excision with 2 to $3 \mathrm{~cm}$ of tumor free surgical margin is prefered for primary lesions smaller than $2 \mathrm{~cm}$. Adjuvant radiotherapy is suggested for tumors greater than $2 \mathrm{~cm}$ after surgical excision. The mortality rate could be decreased in cases with lymphatic metastasis through irradiation of the primary tumor bed and lymph node site after wide local excision and complete lymphatic node dissection. Chemotherapy is the most common preferred modality for the treatment of metastatic disease. In stage IV MCC, cisplatin, doxorubicin, and vincristine or the combination of etoposide and platinum are the most common agents used for chemotherapy (18-20).

MCC is a rare, neuroendocrine cancer of the skin. Primaries in other sites may also be seen. MCC from an unknown primary site is an extremely rare entity. Although the presented patient appears to be an isolated case, MCC should be kept in mind in the differential diagnosis of intrathoracic extrapulmonary malignant masses even without an identifiable primary site.

\section{Conflict of Interest}

No conflict of interest was declared by the authors.

\section{References}

1. Miller RW, Rabkin CS. Merkel cell carcinoma and melanoma: etiological similarities and differences. Cancer Epidemiol Biomarkers Prev 1999;8:153-8.

2. Buell JF, Trofe J, Hanaway MJ, Beebe TM, Gross TG, Alloway RR et al. Immunosuppression and Merkel cell cancer. Transplant Proc 2002;34:1780-1. [CrossRef]

3. The Rockwell Merkel Cell Carcinoma Group. Merkel cell carcinoma: recent progress and current priorities on etiology, pathogenesis, and clinical management. J Clin Oncol 2009;27:4021-6. [CrossRef]

4. Temiz P, Ayhan S, Adiguzel L, Kara E, Okcu G. Gastric Metastasis of Merkel Cell Carcinoma: Case Report. Trakya Univ Tip Fak Derg 2010;27:323-6.
5. Albores-Saavedra J, Batich K, Chable-Montero F, Sagy N, Schwartz AM, Henson DE. Merkel cell carcinoma demographics, morphology, and survival based on 3870 cases: a population based study. J Cutan Pathol 2010;37:20-7. [CrossRef]

6. Huber GF, Khalil M, Falck V, Matthews TW, Dort JC. Merkel cell carcinoma with solitary parotid metastasis: diagnostic dilemma in the absence of a primary site. J Otolaryngol Head Neck Surg 2008;37:E19-21.

7. Fotia G, Barni R, Bellan C, Neri A. Lymph nodal Merkel cell carcinoma: primary or metastatic disease? a clinical case. Tumori 2002;88:424-6.

8. Huang GS, Chang WC, Lee HS, Taylor JA, Cheng TY, Chen CY. Merkel cell carcinoma arising from the subcutaneous fat of the arm with intact skin. Dermatol Surg 2005;31:717-9. [CrossRef]

9. Engels EA, Frisch M, Goedert JJ, Biggar RJ, Miller RW. Merkel cell carcinoma and HIV infection. Lancet 2002;359:497-8. [CrossRef]

10. Lanoy E, Dores GM, Madeleine MM, Toro JR, Fraumeni JF Jr, Engels EA. Epidemiology of nonkeratinocytic skin cancers among persons with AIDS in the United States. AIDS 2009;28;23:385-93. [CrossRef]

11. Lunder EJ, Stern RS. Merkel-cell carcinomas in patients treated with methoxsalen and ultraviolet $A$ radiation. $N$ Engl J Med 1998;22;339:1247-8. [CrossRef]

12. Halata Z, Grim M, Bauman Kl, Friedrich Sigmund. Merkel and his "Merkel cell" morphology, development and physiology: review and new results. Anat Rec 2003;271:225-39. [CrossRef]

13. Toker C. Trabecular carcinoma of the skin. Arch Derm 1972;105:107-10. [CrossRef]

14. Hanly A, Elgart G, Jorda M. Analysis of thyroid transcription factor- 1 and cytokeratin 20 separates Merkel cell carcinoma from small cell carcinoma of the lung. J Cutan Pathol 2000;27:118-20. [CrossRef]

15. McCardle TW, Sondak VK, Zager J, Messina JL. Merkel cell carcinoma: pathologic findings and prognostic factors. Curr Probl Cancer 2010;34:47-64. [CrossRef]

16. Karkos PD, Sastry A, Hampal S, Al-Jafari M. Spontaneous regression of Merkel cell carcinoma of the nose. Head Neck 2010;32:411-4.

17. Silberstein E, Koretz M, Cagnano E, Katchko L, Rosenberg L. Neuroendocrine (Merkel cell) carcinoma in regional lymph nodes without primary site. Isr Med Assoc J 2003;5:450-1.

18. Bichakjian CK, Lowe L, Lao CD, Sandler HM, Bradford CR, Johnson TM et al. Merkel cell carcinoma: critical review with guidelines for multidisciplinary management. Cancer 2007;110:1-12. [CrossRef]

19. Koh CS, Veness MJ. Role of definitive radiotherapy in treating patients with inoperable Merkel cell carcinoma: the Westmead Hospital experience and a review of the literature. Australas $J$ Dermatol 2009;50:249-56. [CrossRef]

20. Asioli S, Righi A, Volante M, Eusebi V, Bussolati G. p63 expression as a new prognostic marker in merkel cell carcinoma. Cancer 2007;110:640-7. [CrossRef] 